\title{
SUPEROXIDE- AND NO-DEPENDENT MECHANISMS OF ANTITUMOR AND ANTIMETASTATIC EFFECT OF L-ARGININE HYDROCHLORIDE AND COENZYME $\mathbf{Q}_{10}$
}

\author{
A.P. Burlaka, ${ }^{1, *}$, I.I. Ganusevich ${ }^{1}$, V.V. Golotiuk ${ }^{2}$, A.V. Vovk', S.M. Lukin ${ }^{1}$ \\ ${ }^{1}$ R.E. Kavetsky Institute of Experimental Pathology, Oncology and Radiobiology, NAS of Ukraine, \\ Kyiv 03022, Ukraine \\ ${ }^{2}$ Ivano-Frankivsk National Medical University, Ivano-Frankivsk 76018, Ukraine
}

\begin{abstract}
Aim: To study the redox-dependent mechanism of antiradical, antitumor and antimetastatic action of L-arginine hydrochloride ( $\mathrm{L}$-Arg) and coenzyme $\mathrm{Q}_{10}\left(\mathrm{CoQ}_{10}\right)$ in vivo. Materials and Methods: The study was performed on $\mathrm{C}_{57} \mathrm{Bl}$ mice with transplanted Lewis lung carcinoma treated by intraperitoneal injections of L-Arg at low or high doses (60 and $360 \mathrm{mg} / \mathrm{kg} \mathrm{body} \mathrm{weight),}$ $\mathrm{CoQ}_{10}(0.2$ and $1.2 \mathrm{mg} / \mathrm{kg}$ body weight) or their combinations. Electron paramagnetic resonance was applied for analysis of mitochondrial electron transport chain, $\mathrm{CoQ}_{10}$ levels, free iron (FI), the level of NO, and the rate of superoxide radical generation. The activity of matrix metalloproteinase (MMP)-2 and -9 in tumor tissue was determined by zymography method in polyacrylamide gel. Results: Administration of L-Arg at high doses caused an inhibition of tumor growth by $48 \pm \mathbf{8 . 0 \%}$, increase of superoxide radical generation rate and NO levels to a value of $1.23 \pm 0.14$ and $2.26 \pm 0.31 \mathrm{~nm} / \mathrm{g}$ tissue $\cdot$ min, and decreased activity of MMP-2 and -9 (3.55 \pm 0.8 and $4.8 \pm 1.0$ r.u., respectively). Treatment with L-Arg at low doses stimulated tumor growth and increased the levels of MMP-2 and -9 activities (8.44 \pm 2.7 and $9.8 \pm 3.1$ r.u., respectively). Administration of $\mathrm{CoQ}_{10}$ at high doses significantly decreased superoxide radical generation rate to the values of $0.44 \pm 0.09 \mathrm{~nm} / \mathrm{g}$ tissue $\cdot$ min, levels of free iron and NO, and caused tumor growth inhibition by $54 \pm 11.3 \%$. The combined use of $\mathrm{L}$-Arg and $\mathrm{CoQ}_{10}$ at high doses caused tumor growth inhibition by $51 \pm 7.4 \%$ compared to Lewis lung carcinoma-bearing untreated animals $(\mathrm{p}<0.05)$. Conclusions: Administration of $\mathrm{L}$-Arg and $\mathrm{CoQ}_{10}$ caused the dose-dependent effect on the rate of generation of superoxide radicals, level of ubisemyquinone, complexes NOFeS-proteins, levels of FI and NO. L-Arg at low doses positively modulated MMP-9 activity that promoted tumor progression. Upon combined use of $\mathrm{L}-\mathrm{Arg}$ and $\mathrm{CoQ}_{10}$, superoxide radicals and NO form the redox state that causes decrease of MMP-2, $\mathbf{- 9}$ activities with consequent inhibition of tumor invasion and metastasis.
\end{abstract}

Key Words: L-arginine, coenzyme $\mathrm{Q}_{10}$, superoxide radical, nitric oxide, matrix metalloproteinase, Lewis lung carcinoma.

One of the approaches to search for innovative anticancer agents with fundamentally different mechanism of action is the use of compounds - donors of nitric oxide (NO), which can modulate the levels of $\mathrm{NO}$ and other regulators of transport rate of electrons in the electron transport chain in mitochondria. Normally functioning mitochondrial metabolism is a process of fine-adjustable dynamic balance of thousands of anabolic and catabolic reactions and cell signaling systems. Since NO is the key signaling molecule in tumor-induced angiogenesis, its antitumor activity can be manifested at least due to its ability to regulate angiogenic pathway [1-5].

Coenzyme $Q_{10}\left(C_{0} Q_{10}\right)$ plays the key role in the mechanism of functioning of the power generating cell system and in the formation of redox potential in mitochondria through the regulation of superoxide radical generation to control gene transcription and cellular and extracellular signaling factors. Physiological levels of $\mathrm{CoQ}_{10}$ in plasma are $0.68-1.1 \mu \mathrm{mol} / \mathrm{l}$ and are supported mainly by endogenous synthesis and to a lesser extent by products of exogenous origin. Activity of $\mathrm{CoQ}_{10}$ decreases with aging as well as in various pathologies, including diabetes, chronic heart failure,

Submitted: February 16, 2016.

*Correspodence: E-mail: apburlaka@gmail.com

Abbreviations used: $\mathrm{Co}_{10}$ - coenzyme $\mathrm{Q}_{10}$; EPR - electron paramagnetic resonance; $\mathrm{FI}$ - free iron; L-Arg - L-arginine hydrochloride; LLC - Lewis lung carcinoma; MMP - matrix metalloproteinase; $\mathrm{NO}$ - nitric oxide; $\mathrm{O}_{2}$ - - superoxide radical. myocardial infarction and cancer [6]. There is a growing amount of evidence in favor of the use of food additives with $\mathrm{CoQ}_{10}$ for prevention and treatment of pathological conditions, NO donors and other regulators of electron transport in mitochondria, including $\mathrm{CoQ}_{10}$ are explored as anticancer agents [7, 8]. However, mechanisms of their action have been studied insufficiently. The matrix metalloproteinases (MMPs), which play a role in tumor invasion and metastasis $[9,10]$, are redoxdependent enzymes [11-13], therefore, they may be involved in the realization of anti-tumor effects of compounds-regulators of electron transport [14, 15].

The aim of the study was to investigate the redoxdependent mechanism of anti-radical, antitumor and antimetastatic action of $\mathrm{L}-\mathrm{Arg}$ and $\mathrm{Co}_{10}$ in vivo.

\section{MATERIALS AND METHODS}

The study was performed on $84 \mathrm{C}_{57} \mathrm{BI}$ male mice weighting $22.4 \pm 1.12 \mathrm{~g}$ bred in animal facility of R.E. Kavetsky Institute of Experimental Pathology, Oncology and Radiobiology of the NAS of Ukraine. The animals were kept on a standard diet. Animal study protocols and operation procedures were carried out in accordance with the main requirements to keeping and working with laboratory animals and to the rules of local Bioethics Committee.

Lewis lung carcinoma (LLC) was used as a tumor model. LLC cells ( $5 \cdot 10^{5}$ cells per animal) were transplanted subcutaneously [16]. The compounds (L-Arginine hydrocloride (L-Arg) (Sigma, USA), 
$\mathrm{CoQ}_{10}$ (Sigma, USA)) were administered intraperitoneally daily for 10 days at low or high doses: LArg -60 and $360 \mathrm{mg} / \mathrm{kg}$ body weight; $\mathrm{CoQ}_{10}-0.2$ and $1.2 \mathrm{mg} / \mathrm{kg}$ body weight. The animals were distributed into 8 experimental groups; I - intact animals $(n=10)$; II - tumor control $(n=11)$; III and IV - animals with tumors treated with high $(n=12)$ and low $(n=10)$ doses of L-Arg, respectively; $\mathrm{V}$ та $\mathrm{VI}$ - animals with tumors treated with high $(n=10)$ and low $(n=10)$ doses of $\mathrm{CoQ}_{10}$, respectively; VII and VIII - animals with tumors treated with high $(n=10)$ and low $(n=10)$ doses of L-Arg and $\mathrm{CoQ}_{10}$, respectively. Animals of group II received daily intraperitoneal injections of physiological saline at corresponding volume for 10 days and served as a positive control.

The research of the electron transport chain in mitochondria, $\mathrm{CoQ}_{10}$ levels in mitochondria and free iron $(\mathrm{FI})$ in tumor cells was performed by electron paramagnetic resonance (EPR) method with computerized spectrometer RE-1307 using the technology of low-temperature stabilization of biological material $(77 \mathrm{~K})$. The rate of superoxide radical generation by mitochondria of cells was determined by EPR method using a spin trap (2,2,6,6,-tetrametyl-4-oxypiperidine) at the room temperature in a special paramagnetic pure quartz cuvette. The level of NO in the tumor tissue was investigated by EPR using the Spin Traps technology (spin trap - diethyl dithiocarbamates (Sigma)) at the temperature of $77 \mathrm{~K}$ [13].

The activity of MMP-2 and -9 in tumor tissue was determined by zymography method in polyacrylamide gel (with addition of gelatin as a substrate) based on SDS-electrophoresis of proteins [17].

The tumor volume was determined by the formula 1 :

$$
V=(\pi / 6) \cdot D 1 \cdot D 2 \cdot D 3,(1)
$$

where $V$ - tumor volume $\left(\mathrm{mm}^{3}\right)$; D1, D2, D3 - tumor length, width, and height.

The number of metastases was counted, and their volume - by the formula 1.

The antitumor activity of the studied compounds was evaluated by tumor growth inhibition:

$$
G_{\%}=\left(v_{c}-v_{e}\right) / m_{k} \cdot 100 \%,(2)
$$

where $\mathrm{G}_{\%}$ - percentage of tumor growth inhibition by volume; $v_{c}-$ average tumor volume in the control; $\mathrm{v}_{\mathrm{e}}$ - average tumor volume in the study group.

Statistical analysis of the obtained data was performed with the use of Origin 7.0 program and Student's $t$-criterion. The data were presented as the mean with the standard deviation $(M \pm S D)$. The differences were considered significant at $\mathrm{p}<0.05$.

\section{RESULTS AND DISCUSSION}

The results of EPR study of LLC are shown in Fig. 1.

In tumor cells of group II (EPR spectrum 1) there were registered the low levels of free radical form of $\mathrm{CoQ}_{10}-$ ubisemiquinone $(\mathrm{g}=2.00)-0.15 \pm$ 0.02 r.u., Fe-S-protein $\mathrm{N}-2(\mathrm{~g}=1.94)$ responsible for coupling of oxidation and phosphorylation $-0.14 \pm$ 0.01 r.u. Also, there was noted an accumulation of high levels of FI $(g=2.20-2.40)-0.86 \pm 0.08$ r.u., the level of NOFe-S-protein complexes was $0.18 \pm 0.02$ r.u.

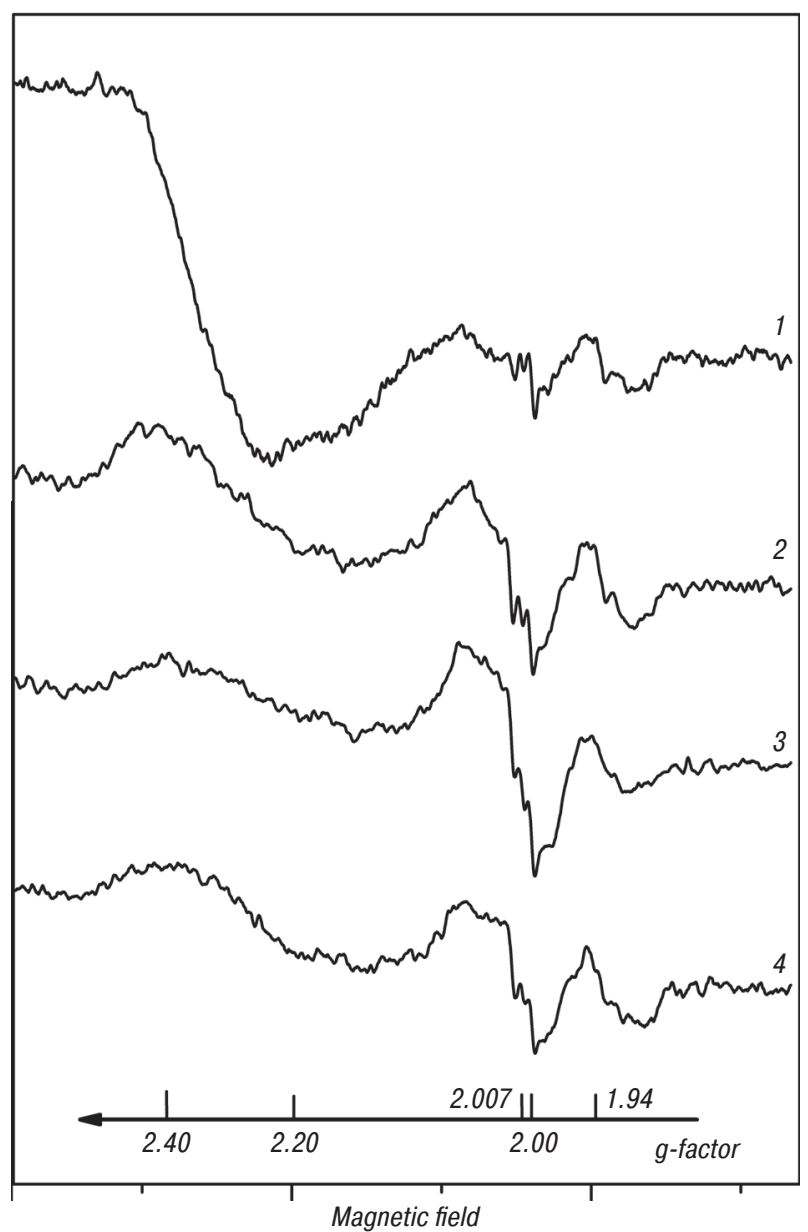

Fig. 1. Effect of $L-A r g$ and $C_{0} Q_{10}$ at high doses on mitochondrial electron transport chain in LLC cells: 1 - tumor of mice in group II; 2 - tumor of mice in group III; 3 - tumor of mice in group $\mathrm{V} ; 4$ - tumor of mice in group $\mathrm{VII}$

In animals injected with L-Arg at high doses, nanomolar levels of NO in the tumor tissue were generated, what caused 2.3-fold decrease of Fl level compared to that in group II $(p<0.05)$. Under these conditions, there were recorded significant increase of the levels of ubisemyquinone up to $0.21 \pm 0.02$ r.u., and NOFeS-proteins complexes in the mitochondrial electron transport chain (up to $0.48 \pm 0.02$ r.u. ), while activity of FeS-protein $\mathrm{N}-2$ remained unaltered $(0.14 \pm$ 0.013 r.u.).

Administration of $\mathrm{CoQ}_{10}$ resulted in the decreased Fl content in tumor tissue of animals $(0.21 \pm 0.02$ r.u.) compared to groups II and III ( $p<0.05)$, and increased formation of NO-FeS-proteins complex $(0.58 \pm$ 0.04 r.u.). The level of ubisemyquinone in the I complex of mitochondrial respiratory chain was $0.22 \pm$ 0.01 r.u. what was significantly lower compared with group II; $\mathrm{p}<0.05$ ); activity of FeS-protein $\mathrm{N}-2$ was $0.11 \pm 0.02$ r.u. $\mathrm{CoQ}_{10}$, providing mitochondria with ubiquinone (NADH-ubiquinone-oxidoreductase and succinate dehydrogenase complexes), promotes the restoration of oxidative phosphorylation via its elevation in the electron transport chain.

The combined therapy with $\mathrm{L}$-Arg and $\mathrm{CoQ}_{10}$ resulted in the decrease of Fl level $-0.28 \pm 0.03$ r.u. compared to group II $(p<0.05)$, ubisemyquinone $(0.15 \pm 0.01$ r.u. $)$ and NOFeS-proteins complexes $(0.38 \pm 0.04$ r.u. $)$ 
compared to groups III and IV ( $p<0.05$ ), increase of FeS-protein N-2 activity $-0.14 \pm 0.02$ (compared to group IV; $p<0.05$ ).

Fig. 2 shows the data on the rate of generation of superoxide radicals by LLC cells. In the tumors of group II the value was $0.75 \pm 0.13 \mathrm{~nm} / \mathrm{g}$ tissue $\cdot \mathrm{min}$, while in the lungs of intact animals it was equal to $0.19 \pm$ $0.03 \mathrm{~nm} / \mathrm{g}$ tissue $\cdot \mathrm{min}$. In the case of administration of high doses of L-Arg, the rate of superoxide radical generation was $1.23 \pm 0.14 \mathrm{~nm} / \mathrm{g}$ tissue $\cdot \min$, that was significantly higher than corresponding values of group II $(p<0.05)$. Therapy with L-Arg at low doses did not influence on this index $(0.78 \pm 0.22 \mathrm{~nm} / \mathrm{g}$ tissue $\cdot$ min). The use of high doses of $\mathrm{CoQ}_{10}$ caused nearly 2 -fold decrease in levels of superoxide radicals $(0.44 \pm 0.09 \mathrm{~nm} / \mathrm{g}$ tissue $\cdot \mathrm{min})$ in mitochondria of tumor cells compared to group II ( $p<0.05)$. After administration of low $\mathrm{CoQ}_{10}$ doses this index did not change $(0.62 \pm 0.08 \mathrm{~nm} / \mathrm{g}$ tissue $\cdot \mathrm{min})$. Combined administration of L-Arg and $\mathrm{CoQ}_{10}$ at low doses reduced the superoxide radical generation rate in mitochondria of tumor cells $(0.32 \pm 0.04 \mathrm{~nm} / \mathrm{g}$ tissue $\cdot \mathrm{min}) \mathrm{com}$ pared with groups II, III, IV, VI ( $p<0.05)$, where as high doses of this compounds reduced this index to $0.65 \pm$ $0.09 \mathrm{~nm} / \mathrm{g}$ tissue $\cdot$ min what was lower than in group III $(p<0.05)$. Thus, the regulators of the electron transport rate in mitochondrial respiratory chain decreased the rate of superoxide radical generation to corresponding levels in a dose dependent manner.

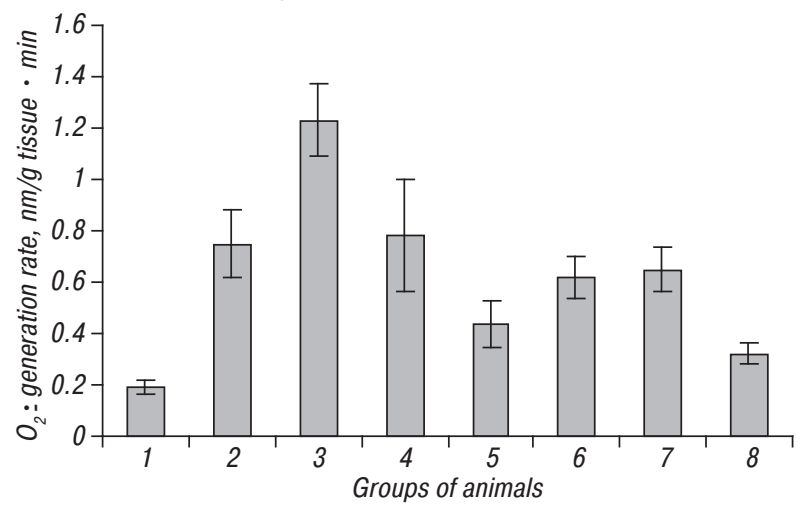

Fig. 2. The rate of superoxide generation $\left(\mathrm{O}_{2}^{-}\right)$in the mitochondria of cells: 1 - lungs of intact mice; 2 - tumor control; 3 tumors of mice that administered high doses of L-Arg; 4 - low doses of L-Arg; 5 - tumors of mice treated with high doses of $\mathrm{CoQ}_{10} ; 6$ - low doses of $\mathrm{CoQ}_{10} ; 7$ - tumors of mice treated with high doses of L-Arg and $\mathrm{CoQ}_{10}$ and $8-\mathrm{L}$-Arg and $\mathrm{CoQ}_{10}$ at low doses. $p<0.05$ compared to tumor control (group II)

Fig. 3 shows the results of the research of NO content in tumor cells. In the tumor bearing animals this rate was $1.95 \pm 0.21 \mathrm{~nm} / \mathrm{g}$ tissue $\cdot$ min, which exceeded the rate in the group of intact animals $-1.45 \pm$ $0.18 \mathrm{~nm} / \mathrm{g}$ tissue $\cdot \min (p<0.05)$. NO level in the tumor after administration of high doses of L-Arg increased up to $2.26 \pm 0.31 \mathrm{~nm} / \mathrm{g}$ tissue $\cdot \min$ versus $1.58 \pm$ $0.19 \mathrm{~nm} / \mathrm{g}$ tissue $\cdot \mathrm{min}$ in the case of low dose L-Arg treatment, and the difference between these indexes is statistically significant. The levels of NO is the cases of administration of high and low doses of $\mathrm{CoQ}_{10}$ were $1.51 \pm 0.12$ and $1.62 \pm 0.23 \mathrm{~nm} / \mathrm{g}$ tissue $\cdot \mathrm{min}$, respectively. Combined therapy with L-Arg and $\mathrm{CoQ}_{10}$ at high doses resulted in the increased level of NO up to the values of $2.2 \pm 0.3 \mathrm{~nm} / \mathrm{g}$ tissue $\cdot$ min compared with groups IV, V, VI $(p<0.05)$, whereas in the case of low dose combined treatment this index $(1.47 \pm$ $0.09 \mathrm{~nm} / \mathrm{g}$ tissue $\cdot \min$ ) was significantly lower than in groups II, III and VII $(p<0.05)$. Therefore, the NO donor and its combined use with $\mathrm{CoQ}_{10}$ at high doses cause the significant increase of $\mathrm{NO}$ levels in tumor cells, which is a positive factor in the antitumor and antimetastatic therapy.

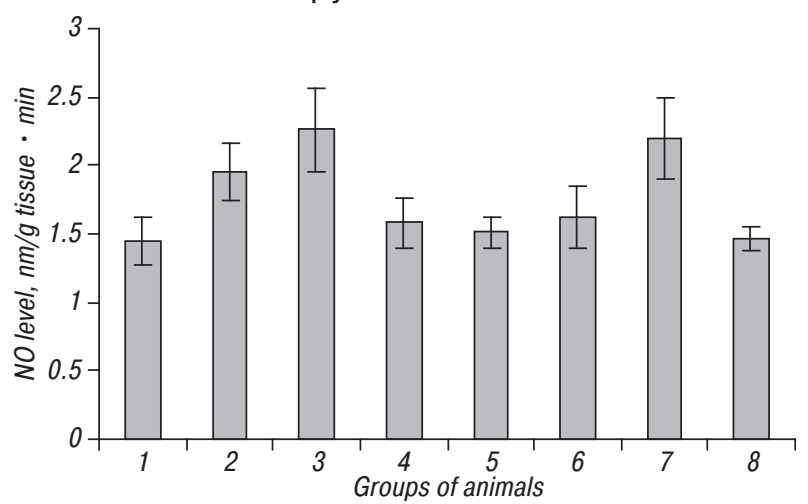

Fig. 3. The level of NO in the mitochondria of cells: 1 - lungs of intact mice; 2 - tumor control; 3 - tumors of mice treated with high doses of L-Arg; 4 - low doses of L-Arg; 5 - tumors of mice treated with high doses of $\mathrm{CoQ}_{10} ; 6$ - low doses of $\mathrm{CoQ}_{10}$; 7 - tumors of mice treated with high doses of L-Arg and $\mathrm{CoQ}_{10}$; $8-\mathrm{L}-\operatorname{Arg}$ and $\mathrm{CoQ}_{10}$ at low doses. $\mathrm{p}<0.05$ compared with tumor control (group II)

Administration of L-Arg at high doses causes an increase in NO level, augments mitochondrial damage, intensificates generation of superoxide radicals, increases the rate of oxidation-induced mutations of mtDNA, and induces tumor cell apoptosis [8]. $\mathrm{NO}$ at low doses promotes tumor invasiveness, angiogenesis and immune tolerance $[1,7]$. Administration of $\mathrm{CoQ}_{10}$ at high doses to animals with LLC significantly reduced NO levels in tumor cells compared to control animals (see Fig. 3). Combined use of L-Arg and $\mathrm{CoQ}_{10}$ at low doses caused an increase of NO levels in tumor cells compared to group II $(p<0.05)$.

Summarizing the obtained information, one may suppose that high doses of regulators of the electron transport rate based on $\mathrm{NO}$ and $\mathrm{CoQ}_{10}$ donors cause correlating effects at the level of mitochondria. These compounds influence regulation of superoxide radical generation rate and $\mathrm{NO}$ level, and subsequently modulate MMP-2 and -9 activities. Activity of MMP-2 and -9 in tumor tissue of the control animals greatly exceeded these indices in the lungs of the intact animals and correlated with the values of the superoxide radicals generation rate by tumor cells in these groups of animals (Fig. 2, 4, 5). In tumors of animals injected with high doses of L-Arg a significant (almost 2 times; $p<0.05$ ) decrease in activity of both gelatinases was observed compared with the control group, which could be a consequence of the ultrahigh rate of superoxide radical generation. On the contrary, low doses of L-Arg caused an insignificant increase in activity of MMP-2 in tumor tissue compared to the control that was due to the regulatory impact of the increase 
in rate of superoxide radical generation in tumor cells of this group of animals (see Fig. 2, 4, 5). Treatment with both high and low doses of $\mathrm{CoQ}_{10}$ led to the significant superoxide regulated decrease (1.7-2.3 times; $p<0.05$ ) in activity of both gelatinases, compared to group II (see Fig. 2, 4, 5).

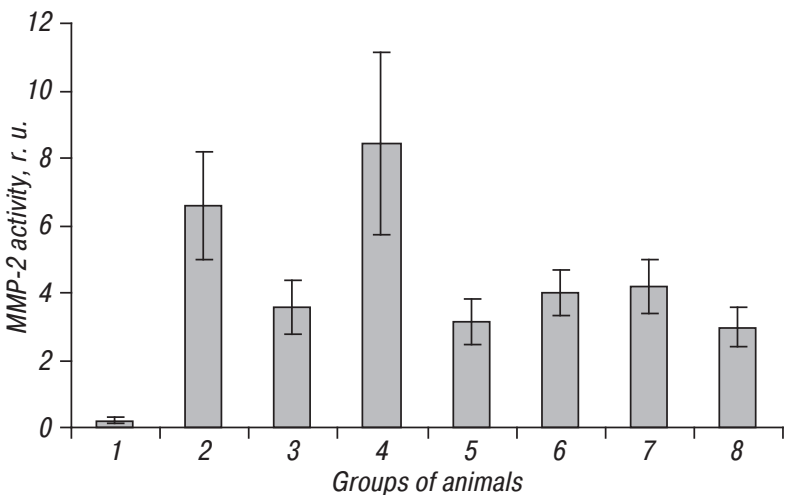

Fig. 4. Activity of MMP-2 (r.u.): 1 - lungs of intact mice; 2 - tumor control; 3 - tumors of mice treated with high doses of L-Arg; 4 - low doses of L-Arg; 5 - tumors of mice treated with high doses of $\mathrm{CoQ}_{10} ; 6$ - low doses of $\mathrm{CoQ}_{10} ; 7$ - tumors of mice treated with high doses of L-Arg and $C_{0} Q_{10} ; 8-L-A r g$ and $\mathrm{CoQ}_{10}$ at low doses. $\mathrm{p}<0.05$ compared to tumor control (group II)

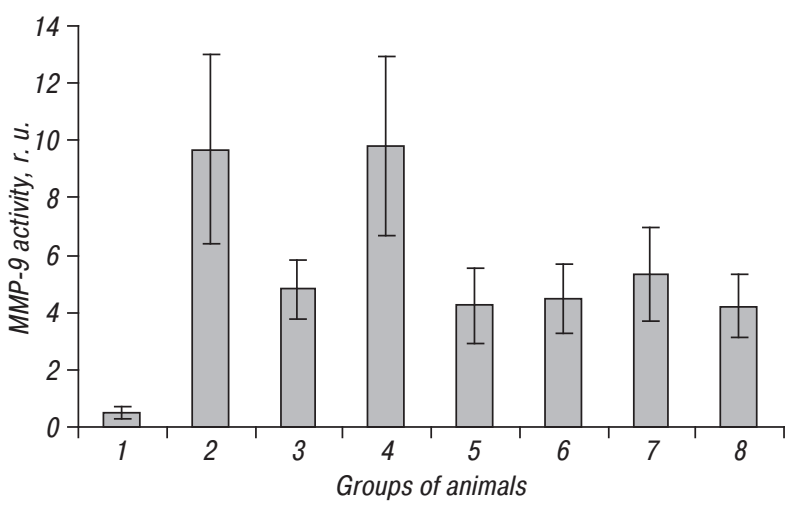

Fig. 5. Activity of MMP-9 (r.u.): 1 - lungs of intact mice; 2 tumor control; 3 - tumors of mice treated with high doses of L-Arg; 4 - low doses of L-Arg; 5 - tumors of mice treated with high doses of $\mathrm{CoQ}_{10} ; 6$ - low doses of $\mathrm{CoQ}_{10} ; 7$ - tumors of mice treated with high doses of L-Arg and $\mathrm{CoQ}_{10} ; 8$ - L-Arg and $\mathrm{CoQ}_{10}$ at low doses. $\mathrm{p}<0.05$ compared to tumor control (group II)

Activity of MMP-2 and -9 in tumors of animals injected by both substances at high or low doses was significantly below the control values $(p<0.05)$. In this case (Table 1, 2) low gelatinase activity levels corresponded to slower primary tumor growth and decreased metastasis in experimental animals. In the control group and group of animals injected with low doses of L-Arg, high gelatinase activity levels were observed in tumor tissue along with accelerated LLC growth and metastasis.

Tables 1 and 2 shows the data on antitumor and antimetastatic activity of L-Arg and $\mathrm{CoQ}_{10}$ administered at low and high doses. As one may see, the antitumor and antimetastatic activity of L-Arg differed significantly depending on the level of NO in tumor cells $(p<0.05)$. Thus, high doses of the compound caused a decrease in the tumor volume by $48.0 \pm 8.0 \%$, while low doses stimulated its growth, number of metastases and their volume $(p<0.05)$. Treatment with $\mathrm{CoQ}_{10}$ at high and low doses resulted in inhibition of the tumor growth by $54.0 \pm$ 11.3 and $39.0 \pm 5.4 \%$, respectively, the difference between these indexes was insignificant. Combined effect of both compounds at high doses caused tumor growth inhibition by $51.0 \pm 7.4 \%$. Thus, a NO donor and $\mathrm{CoQ}_{10}$ showed the antitumor and antimetastatic activity, and the pro- and anti-tumor effect of NO depended on its dose. These data were in accordance with those of other authors who demonstrated the dual effect of NO donors [1, 7, 8]. Superoxide regulated MMP-2 and -9 mediate anti-tumor effects of L-Arg and $\mathrm{CoQ}_{10}$ at the level of intercellular matrix proteolysis, because reduced activity of gelatinases contributes to inhibition of migration, dissemination of tumor cells and formation of metastatic centers.

Table 1. Antitumor activity of $L-A r g$ and $C_{0} Q_{10}$

\begin{tabular}{|c|c|c|c|c|}
\hline \multirow[b]{3}{*}{$\begin{array}{c}\text { Groups } \\
\text { of animals }\end{array}$} & \multicolumn{4}{|c|}{ Doses } \\
\hline & \multicolumn{2}{|c|}{ High } & \multicolumn{2}{|c|}{ Low } \\
\hline & $\begin{array}{l}\text { Tumor vo- } \\
\text { lume, } \mathrm{mm}^{3}\end{array}$ & $\begin{array}{l}\text { Inhibition } \\
\text { of tumor } \\
\text { growth, \% }\end{array}$ & $\begin{array}{l}\text { Tumor vo- } \\
\text { lume, } \mathrm{mm}^{3}\end{array}$ & $\begin{array}{l}\text { Inhibition } \\
\text { of tumor } \\
\text { growth, \% }\end{array}$ \\
\hline Tumor control & $1600 \pm 95$ & - & $1600 \pm 95$ & - \\
\hline L-Arg & $832 \pm 115^{1}$ & $48 \pm 8.0$ & $1840 \pm 125^{1}$ & $15 \pm 2.6$ \\
\hline $\mathrm{CoQ}_{10}$ & $736 \pm 137^{1}$ & $54 \pm 11.3$ & $970 \pm 112^{1,2}$ & $39 \pm 5.4$ \\
\hline $\mathrm{L}-\mathrm{Arg}$ and $\mathrm{Co}_{0} \mathrm{Q}_{10}$ & $784 \pm 104^{1}$ & $51 \pm 7.4$ & $1410 \pm 99^{2,3}$ & $12 \pm 3.1$ \\
\hline
\end{tabular}

Note: ${ }^{1} p<0.05$ compared to tumor control (group II); ${ }^{2} p<0.05$ compared to animals treated with L-Arg; ${ }^{3} p<0.05$ compared to animals treated with $\mathrm{CoQ}_{10}$.

Table 2. Antimetastatic activity of L-Arg and $\mathrm{C}_{0} \mathrm{Q}_{10}$

\begin{tabular}{lcccc}
\hline \multirow{4}{*}{$\begin{array}{c}\text { Groups } \\
\text { of animals }\end{array}$} & \multicolumn{2}{c}{ High } & \multicolumn{2}{c}{ Low } \\
\cline { 2 - 5 } & $\begin{array}{c}\text { Number } \\
\text { of meta- } \\
\text { stases }\end{array}$ & $\begin{array}{c}\text { Volume } \\
\text { of metasta- } \\
\text { ses, } \mathrm{mm}^{3}\end{array}$ & $\begin{array}{c}\text { Number } \\
\text { of meta- } \\
\text { stases }\end{array}$ & $\begin{array}{c}\text { Volume } \\
\text { of metasta- } \\
\text { ses, } \mathrm{mm}^{3}\end{array}$ \\
\hline Tumor control & $6.8 \pm 3.1$ & $139 \pm 54$ & $6.8 \pm 3.1$ & $139 \pm 54$ \\
L-Arg $_{\text {CoQ }}$ & $3.6 \pm 1.1$ & $79 \pm 21$ & $10.8 \pm 1.1$ & $212 \pm 33$ \\
${\text { L-Arg and } \mathrm{CoQ}_{10}}$ & $3.1 \pm 2.3$ & $76 \pm 13$ & $4.7 \pm 2.3^{1}$ & $89 \pm 13^{1}$ \\
\hline
\end{tabular}

Note: ${ }^{1} p<0.05$ compared to animals treated with L-Arg; ${ }^{2} p<0.05$ compared to animals treated with $\mathrm{CoQ}_{10}$.

Reprogramming of mitochondria metabolism, disorders of redox homeostasis in mitochondria electron transport chain are characteristic for malignant tumor cells. That is accompanied by the replacement of fourto single-electron restoration of oxygen molecule with subsequent formation of superoxide radicals. Increased production of superoxide radicals in tumor cells promotes cancer progression through the activation of signaling pathways that regulate metabolic changes, proliferation, angiogenesis and metastasis [18, 19].

$\mathrm{CoQ}_{10}$ plays the role of electron transporter in complexes I, II and III electron transport chain of mitochondria. Reduced form of $\mathrm{CoQ}_{10}$ protects the membrane, proteins and mitochondrial DNA from oxidative agents, including superoxide radicals. We have found that $\mathrm{CoQ}_{10}$ realizes its protective function restoring the electron transport process and reducing the level of generation of superoxide radicals by mitochondria in LLC cells. These data are in agreement with the data on protective effect of $\mathrm{CoQ}_{10}$ toward UV irradiated astrocytes [20] and fibroblasts [21].

Recent studies have shown that NO takes part in the regulation of tumor cell proliferation, in particular, in its inhibition and induction of apoptosis, which is possible due 
to the ability of $\mathrm{NO}$ to inactivate iron-containing enzyme involved in the synthesis of ATP and DNA replication. Activation of NO synthase (NOS) and increased levels of NO generation can have both antitumor effect, and promote the initiation and progression of tumor [2]. The use of different doses of NO may allow to regulate phenotypic responses through molecular mechanisms that form pro- and antitumor effects.

Our results showed a dose-dependent action of L-Arg on redox-dependent processes in LLC. Thus, the use of L-Arg at high doses leads to increased levels of $\mathrm{NO}$ and superoxide radicals in mitochondria of LLC cells, increasing their cytotoxic effect by formation of peroxynitrite, which can cause DNA damage and initiation of apoptosis. Similar results were obtained in the study of dose-depending action of NO donors on proliferation and apoptosis in Ehrlich ascites carcinoma [22]. It should be noted that the use of NO donors at low doses enhances the functional activity of mitochondria, stimulates the formation of superoxide radicals in physiological range and, conversely, at high doses - depresses mitochodrial respiration, inhibits the incorporation of arachidonic acid and activates its output.

In modern studies of suppression, stabilization or enhancement of the degradation of extracellular matrix are considered critical characteristics of malignant progression [9] as well as expression level of gelatinases is thought to be associated with the metastasis and overall survival of cancer patients [10]. Known synthetic inhibitors inhibit MMP activity in in vitro experiments and in animal models, but failed in clinical trials [23]. On the other hand, some studies have shown that antioxidants $[15,24]$, including $\operatorname{CoQ}_{10}[25,26]$, suppress tumor growth by inhibition of MMP activity via intracellular regulation of reactive oxygen species. Our results showed that MMP-2 and -9 mediate antitumor effects of $L-A r g$ and $\mathrm{CoQ}_{10}$ at the level of intercellular matrix proteolysis. Redox-regulated decrease of gelatinases activity promotes inhibition of tumor cell migration, dissemination and formation of metastatic niches.

\section{REFERENCES}

1. Mocellin S, Bronte V, Nitti D. Nitric oxide, a double edged sword in cancer biology: searching for therapeutic opportunities. Med Res Rev 2007; 27: 317-52.

2. Ridnour L, Thomas D, Switzer Ch, et al. Molecular mechanisms for discrete nitric oxide levels in cancer. Nitric Oxide 2008; 19: 73-6.

3. Burlaka AP, Sidorik EP. Radical forms of oxygen and nitrogen oxide in the tumor process. Kyiv: Naukova dumka, 2006. 227 p. (in Ukrainian).

4. Burlaka AP, Sidorik EP. Redox-dependent signal molecules in mechanisms of tumor process. Kyiv: Naukova dumka, 2014. 255 p. (in Ukrainian).

5. Jadeski LC, Lala PK. Nitric oxide synthase inhibition by $\mathrm{N}(\mathrm{G})$-nitro-L-arginine methyl ester inhibits tumorinduced angiogenesis in mammary tumors. Am J Pathol 1999; 155: $1381-90$.

6. Garrido-Maraver Ju, Cordero M, Oropesa-Avila M, et al. Coenzyme $\mathrm{Q}_{10}$ Therapy. Mol Syndromol 2014; 5: 187-97.
7. Cheng H, Wang L, Mollica M, et al. Nitric oxide in cancer metastasis. Cancer Lett 2014; 353: 1-7.

8. Rapozzi V, Pietra E, Zorzet S, et al. Nitric oxidemediated activity in anti-cancer photodynamic therapy. Nitric Oxide 2013; 30: 26-35.

9. Fingleton B. Matrix metalloproteinases: roles in cancer and metastasis. Front Biosci 2006; 11: 479-91.

10. Ganusevich II. Role of matrix metalloproteinases (MMP) in malignancies. I. MMP characteristics, regulation, and prognostic value. Oncology 2010; 12: 10-6 (in Ukrainian).

11. McCormick ML, Gavrila D, Weintraub NL. Role of oxidative stress in the pathogenesis of abdominal aortic aneurysms. Arterioscler Thromb Vasc Biol 2007; 27: 461-9.

12. Castro MM, Rizzi E, Rodrigues GJ, et al. Antioxidant treatment reduces matrix metalloproteinase-2-induced vascular changes in renovascular hypertension. Free Radic Biol Med 2009; 46: 1298-307.

13. Burlaka AP, Sidorik EP, Ganusevich II, et al. Effects of radical oxygen species and NO: formation of intracellular hypoxia and activation of matrix metalloproteinases in tumor tissues. Exp Oncol 2006; 28: 49-53.

14. Panyathep A, Chewonarin $T$, Taneyhill $K$, et al. Antioxidant and anti-matrix metalloproteinases activities of dried longan (Euphoria longana) seed extract. Science Asia 2013; 39: 12-8.

15. Lee SJ, Kim MM. Resveratrol with antioxidant activity inhibits matrix metalloproteinase via modulation of SIRT1 in human fibrosarcoma cells. Life Sci 2011; 88: 465-72.

16. Sophina Z, Goldin A. Experimental evaluation of anticancer drugs in USSR and USA. Moscow: Medicina, 1980. 295 p. (in Russian).

17. DeClerk YA, Perez N, Shimada $\mathrm{H}$, et al. Inhibition of invasion and metastasis in cells transfected with an inhibitor of metalloproteinases. Cancer Res 1992; 52: 701-8.

18. Sabharwal SS, Schumacker PT. Mitochondrial ROS in cancer: initiators, amplifiers or an Achilles' heel? Nat Rev Cancer 2014; 14: 709-21.

19. LB, Chandel NS. Mitochondrial reactive oxygen species and cancer. Cancer Metab 2014; 2: 17.

20. Jing L, He MT, Chang Y, et al. Coenzyme $Q_{10}$ protects astrocytes from ROS-induced damage through inhibition of mitochondria-mediated cell death pathway. Int J Biol Sci 2015; 11: 59-66.

21. Cornelius N, Byron C, Hargreaves I, et al. Secondary coenzyme $\mathrm{Q}_{10}$ deficiency and oxidative stress in cultured fibroblasts from patients with riboflavin responsive multiple Acyl-CoA dehydrogenation deficiency. Hum Mol Genet 2013; 22: 3819-27.

22. Deriagina VP, Ryzhova NI, Krivosheeva LV, et al. Production of nitric oxide metabolites during transplanted tumors growth with different metastatic potential. Biomed Khim 2014; 60: 661-7 (in Russian).

23. Ganusevich II. Role of matrix metalloproteinases (MMPs) in malignancies. II. Participation of MMPs in angiogenesis, invasion and metastasis of tumors. Oncology 2010; 12: 108-17 (in Ukrainian).

24. Park I-H, Kwon E-J, Lee S-J, et al. Quercetin with Antioxidant Activity Inhibits Matrix Metalloproteinase-2 and -9 in HT1080 Cell Line. Cancer Prev Res 2011; 16: 223-30.

25. Bahar M, Khaghani S, Pasalar $\mathrm{P}$, et al. Exogenous coenzyme $\mathrm{Q}_{10}$ modulates MMP-2 activity in MCF-7 cell line as a breast cancer cellular model. Nutr J 2010; 9: 62.

26. Inui M, Ooe M, Fujii K, et al. Mechanisms of inhibitory effects of $\mathrm{CoQ}_{10}$ on UVB-induced wrinkle formation in vitro and in vivo. BioFactors 2008; 32: 237-43. 